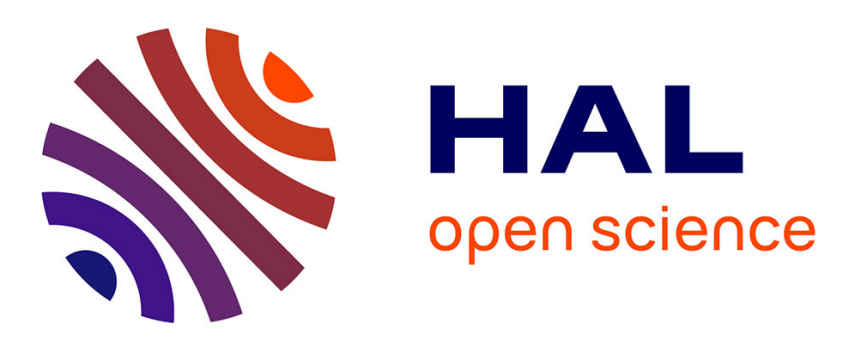

\title{
Reversible elevations of serum creatinine levels but no effect on glomerular filtration during treatment with the direct thrombin inhibitor AZD0837
}

Kajs-Marie Schützer, Maria K. Svensson, Sofia Zetterstrand, Ulf G. Eriksson, Karin Wåhlander

\section{- To cite this version:}

Kajs-Marie Schützer, Maria K. Svensson, Sofia Zetterstrand, Ulf G. Eriksson, Karin Wåhlander. Reversible elevations of serum creatinine levels but no effect on glomerular filtration during treatment with the direct thrombin inhibitor AZD0837. European Journal of Clinical Pharmacology, 2010, 66 (9), pp.903-910. 10.1007/s00228-010-0849-7 . hal-00599459

\section{HAL Id: hal-00599459 \\ https://hal.science/hal-00599459}

Submitted on 10 Jun 2011

HAL is a multi-disciplinary open access archive for the deposit and dissemination of scientific research documents, whether they are published or not. The documents may come from teaching and research institutions in France or abroad, or from public or private research centers.
L'archive ouverte pluridisciplinaire HAL, est destinée au dépôt et à la diffusion de documents scientifiques de niveau recherche, publiés ou non, émanant des établissements d'enseignement et de recherche français ou étrangers, des laboratoires publics ou privés. 


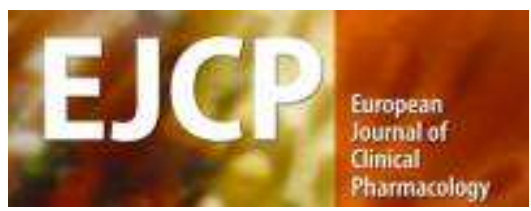

\section{Reversible elevations of serum creatinine but no effect on glomerular filtration during treatment with the direct thrombin inhibitor AZD0837}

\begin{tabular}{|r|l|}
\hline Journal: & European Journal of Clinical Pharmacology \\
\hline Manuscript ID: & EJCP-2010-0097.R1 \\
\hline Type of submission: & Original \\
\hline Date Submitted by the & $29-$ Apr-2010 \\
\hline Complete List of Authors: & $\begin{array}{l}\text { Schützer, Kajs-Marie; AstraZeneca R\&D Mölndal, CVGI Clinical TA } \\
\text { Svensson, Maria; Sahlgrenska University Hospital, Department of } \\
\text { Molecular and Clinical Medicine } \\
\text { Zetterstrand, Sofia; Astrazeneca R\&D Mölndal, CVGI Clinical TA } \\
\text { Eriksson, Ulf; Astrazeneca R\&D Mölndal, CVGI Clinical TA } \\
\text { Wăhlander, Karin; Astrazeneca R\&D Mölndal, CVGI Clinical TA }\end{array}$ \\
\hline \hline
\end{tabular}

\section{$\checkmark$ ScholaroNE"




\title{
Reversible elevations of serum creatinine but no effect on glomerular filtration during treatment with the direct thrombin inhibitor AZD0837
}

K-M Schützer ${ }^{1}$, MK Svensson ${ }^{2}$, S Zetterstrand ${ }^{1}$, UG Eriksson ${ }^{1}$, K Wåhlander $^{1}$

\author{
${ }^{1}$ AstraZeneca R\&D, Mölndal, Sweden \\ ${ }^{2}$ Department of Molecular and Clinical Medicine, Sahlgrenska University Hospital, Gothenburg, \\ Sweden
}

Correspondence: Kajs-Marie Schützer, CVGI Clinical TA, AstraZeneca R\&D Mölndal, S-431 83 Mölndal, Sweden.

E-mail: kajs-marie.schutzer@astrazeneca.com

Tel: +46317762767

Mobile: +46 705656576

Fax: +4631776 3759

AstraZeneca study code: D1250C00033

Keywords: thrombin inhibitor, renal function, glomerular filtration rate, creatinine, tubular secretion, tubular transporter proteins 


\section{ABSTRACT}

Purpose: Reversible mean increases in serum creatinine ( 10\%) have been observed during the clinical investigations of the oral direct thrombin inhibitor AZD0837. The aim of this study was to evaluate whether the increase in s-creatinine is due to a decrease in renal glomerular filtration rate (GFR) or inhibition of tubular secretion of creatinine.

Methods: Thirty healthy subjects aged 60-71 years were included in an open-label, randomised, placebo-controlled, two-way crossover study (D1250C00033) with AZD0837 450 mg extended-release formulation once daily for 8 days. Cimetidine was co-administered on Days 6-8 during both treatment periods. Blood and urine samples were collected for assessment of s-creatinine, s-cystatin $\mathrm{C}$, endogenous creatinine clearance $(\mathrm{CrCl})$ and urinary markers of renal damage. GFR was measured by the plasma clearance of iohexol.

Results: A 6\% increase in mean s-creatinine, but no increase in s-cystatin C, was observed during treatment with AZD0837. Co-administration of cimetidine resulted in a $21 \%$ increase in screatinine. A significant decrease in $\mathrm{CrCl}$ was found during AZD0837 treatment compared with placebo $(-5.73 \mathrm{ml} / \mathrm{min} ; 95 \% \mathrm{Cl}-11.3$ to -0.12$)$. No significant difference in GFR $(-1.6$ $\mathrm{ml} / \mathrm{min} / 1.73 \mathrm{~m}^{2} ; 90 \% \mathrm{Cl}-3.7$ to 0.5$)$ was seen during treatment with AZD0837 versus placebo. No changes in renal damage markers were found during the treatment periods.

Conclusions: An increase in s-creatinine, a decrease in $\mathrm{CrCl}$, but no decrease in GFR, were found during treatment with AZD0837. Findings suggest that inhibition of renal tubular secretion of creatinine is the likely cause of the observed increase in s-creatinine.

Word count $=249$ words 


\section{INTRODUCTION}

Creatinine is a non-protein waste product of creatine phosphate metabolism by skeletal muscle tissue. Creatinine production is continuous and is proportional to muscle mass. Creatinine is freely filtered in the kidney and therefore the serum creatinine (s-creatinine) level is dependent on glomerular filtration rate (GFR), but is also influenced by active renal tubular excretion of creatinine, diet and muscular mass [1;2]. S-creatinine is often used as an indicator of renal function both in clinical practice and during drug development [3].

During drug development, elevations in s-creatinine, raising the question of nephrotoxicity have occasionally been found. Sometimes this may indeed be a reflection of adverse renal effects and in other cases due to a beneficial renal functional effect, such as the renal haemodynamic alterations of angiotensin-converting enzyme inhibitors and angiotensin receptor blockers [4], or due to reversible benign inhibition of the renal tubular secretion of creatinine as seen with cimetidine [5-7].

AZD0837 is an oral direct thrombin inhibitor currently under clinical development for stroke prevention in atrial fibrillation [8;9]. AZD0837 is rapidly absorbed and bioconverted into its active form, AR-H067637, via an intermediate metabolite, AR-H069927 [10-12]. AZD0837 is only to a minor degree excreted into the urine [13]. During clinical development of AZD0837 a reversible increase in mean s-creatinine of approximately $10 \%$ has been found. The objective of the present study was to investigate potential mechanisms for this increase in s-creatinine and to evaluate whether it may be due to a decrease in renal GFR or inhibition of tubular secretion of creatinine.

\section{METHODS}

\section{Subjects}

Healthy men and women, aged 60-75 years, with normal clinical and laboratory findings including a normal renal function ( $>70 \mathrm{ml} / \mathrm{min}$ ), as estimated by creatinine clearance $(\mathrm{CrCl})$ according to the Cockcroft-Gault formula [14], a body mass index of $18-30 \mathrm{~kg} / \mathrm{m}^{2}$ and who gave written, informed consent prior to enrolment were eligible to participate in the study. Exclusion criteria included significant recurrent illness, a history of bleeding or thrombotic disorder, a history of, or ongoing, severe allergy or hypersensitivity, hypersensitivity to X-ray contrast medium, cardiovascular, hepatic or significant gastrointestinal disease, or a positive HIV or hepatitis B or $\mathrm{C}$ test. The use of anticoagulant, antiplatelet (including aspirin), fibrinolytic or nonsteroidal anti-inflammatory drugs was not permitted from 2 weeks prior to the study until completion. 
The study was approved by the independent Institutional Review Board/Research Ethics Committee Berlin, Germany and the national medical agency BfArm, Germany. The study was performed in compliance with the Declaration of Helsinki.

\section{Study design}

This was an open-label, randomised, placebo-controlled, two-way crossover Phase I study (D1250C00033) with two treatment periods of 8 days each, separated by a washout period of 10-21 days as shown in Figure 1. Repeated doses of AZD0837 450 mg extended-release formulation (three $150 \mathrm{mg}$ tablets) were given as a once-daily administration in the morning for 8 days in one period and corresponding placebo tablets were given during the other period. Cimetidine (Tagamet ${ }^{\circledR}$, GlaxoSmithKline) was co-administered on Days 6-8 in both periods in a three-times-daily regimen of $400+400+800 \mathrm{mg}$ as a positive control for inhibition of tubular secretion of creatinine. A pre-entry screening visit, including an overall health examination, was conducted within 14 days prior to the first study day. This comprised a medical history, history of bleeding and thrombotic occurrences, physical examination, 12-lead electrocardiogram and measurement of blood pressure, heart rate and laboratory status (haematology, clinical chemistry, urinalysis and coagulation analysis [activated partial thromboplastin time (APTT)]). Laboratory measurements were repeated during both treatment periods: before administration of study drug on Day 1, on Day 5 and Day 8 before administration, and 7-10 days after completion of last treatment period. Subjects whose 24-hour APTT values after last dose were more than 10 seconds greater than their pre-dose values were required to remain at the study site until the values had normalised.

\section{Assessments of renal function}

\section{Serum creatinine}

S-creatinine was measured before every AZD0837/placebo dose on Days 1-8 and in the mornings of Days 9 and 10. In addition, s-creatinine was measured 12 hours after AZD0837/placebo dose on Days 5 and 8. S-creatinine was analysed by routine spectrophotometry methods (Architect c8000, Abbott GmbH \& Co. KG, Wiesbaden-Delkenheim, Germany).

\section{Serum cystatin $C$}

Serum cystatin $\mathrm{C}$ (s-cystatin $\mathrm{C}$ ), an additional glomerular filtration marker, was determined before every AZD0837/placebo dose on Days 1, 5 and 8 and in the morning of Day 10 [15]. Scystatin $\mathrm{C}$ was analysed by routine methods (Image immunochemistry system, Beckman Coulter GmbH, Krefeld, Germany). 


\section{Glomerular filtration rate}

GFR was determined by plasma clearance of iohexol (iCl) (four-sample method) on Day 5 in each treatment period. lohexol $300 \mathrm{mg} / \mathrm{ml}$ was given as a $5 \mathrm{ml}$ intravenous injection 3 hours after the AZD0837/placebo dose. Blood ( $7.5 \mathrm{ml}$ in heparinised tubes) for determination of the plasma concentration of iohexol was taken at pre-dose and at 1,2 and 4 hours after the injection of iohexol. A standardised high water intake (>1000 ml) was given before injection of iohexol (Omnipaque ${ }^{\circledR}$, Nycomed Amersham Health, Cork, Ireland) to ensure an adequate urine production. The plasma samples for $\mathrm{iCl}$ were analysed using high-performance liquid chromatography (Renalyzer PRX 90, Provalid AB, Lund, Sweden) at the Department of Clinical Chemistry, Sahlgrenska University Hospital, Sweden.

\section{Endogenous creatinine clearance}

Endogenous $\mathrm{CrCl}$ was measured by analysis of 24-hour urine collections on Days 5 and 8 . The bladder was emptied before the urine collection period started. A $10 \mathrm{ml}$ sample was taken from all urine from the total collection period (0-24 hours). A blood sample for analysis of creatinine ( $2.7 \mathrm{ml}$ serum separating tube) was drawn after 12 hours (mid-period). The urine and serum analyses of creatinine were carried out using routine spectrophotometry methods (Architect c8000, Abbott GmbH \& Co. KG, Wiesbaden-Delkenheim, Germany).

\section{Urinary markers of renal damage}

Urinary albumin, immunoglobulin $\mathrm{G}, \alpha_{1}$-microglobulin and $\beta_{2}$-microglobulin were determined in a 12-hour urine collection starting in the evening before the AZD0837/placebo dose on Days 1 and 5. Urinary albumin and creatinine (albumin/creatinine ratio; ACR) were determined in the 24-hour urine collection on Days 5 and 8. Urinary markers were analysed by standard methods at the Department of Clinical Chemistry, Sahlgrenska University Hospital, Gothenburg, Sweden.

\section{Pharmacokinetics}

Plasma samples for measurement of AZD0837, AR-H069927 (the intermediary metabolite) and AR-H067637 (the active form of AZD0837) concentrations were analysed by Analytico Medinet (AM) B.V., the Netherlands. For determination of plasma concentration, reversed-phase liquid chromatography-tandem mass spectrometry after solid-phase extraction was used. The limit of quantification (LOQ) was $10 \mathrm{nmol} / \mathrm{l}$ for all analytes. The method was developed for $250 \mu \mathrm{l}$ human citrate plasma, and plasma concentrations were adjusted for the dilution of blood with citrate buffer in the sampling tubes. AZD0837, AR-H069927 and AR-H067637 were extracted from human plasma by means of an automated solid-phase extraction (extraction columns: $1 \mathrm{ml}$ 
ISOLUTE C6-column 25 mg). Chromatography was performed on an Hypersil HyPurity C18, $5 \mu \mathrm{m}(100 \mathrm{~mm} \times 2.1 \mathrm{~mm})$ protected by a C18 pre column at a flow of $0.75 \mathrm{ml} / \mathrm{min}$. The mass spectrometer used was an Applied Biosystems/MDS Sciex API-3000 system with turbo-ion spray interface and Analyst Software. Cimetidine concentrations in plasma were determined by PRA International - Early Development Services, Bioanalytical Laboratory, the Netherlands, using liquid chromatography with ultraviolet detection after solid-phase extraction. The LOQ was $0.10 \mu \mathrm{g} / \mathrm{ml}$.

\section{Statistical analysis}

This trial set out to test whether AZD0837 would affect GFR. A clinically relevant effect on GFR was considered to be $10 \%$ (for example, a change in GFR of $7 \mathrm{ml} / \mathrm{min} / 1.73 \mathrm{~m}^{2}$ in a population with a mean GFR of $70 \mathrm{ml} / \mathrm{min} / 1.73 \mathrm{~m}^{2}$ ), and the "no effect limit" was set to a difference of -5 $\mathrm{ml} / \mathrm{min} / 1.73 \mathrm{~m}^{2}$. With 24 evaluable subjects the power to conclude "no effect" was $90 \%$, given that AZD0837 did not affect GFR, at the significance level of $5 \%$, and assuming a standard deviation of $8 \mathrm{ml} / \mathrm{min}$ of the difference in GFR. Since the previously observed elevation in screatinine with AZD0837 could correspond to a potential reduction in GFR, only a reduction in GFR was considered clinically relevant, and a one-sided test of significance was therefore used. GFR was analysed in an analysis of variance (ANOVA) model with fixed factors for treatment, sequence and period, and a random factor for subject. To test for "no effect" a two-sided 90\% confidence interval $(\mathrm{Cl})$ for differences in treatment means was constructed. If the lower bound of this $\mathrm{Cl}$ (corresponding to the lower bound of the one-sided $95 \% \mathrm{Cl}$ ) was no less than -5 $\mathrm{ml} / \mathrm{min}$ it was to be concluded that there was no clinically relevant effect on GFR by AZD0837. Endogenous $\mathrm{CrCl}$, s-creatinine and s-cystatin $\mathrm{C}$ were analysed using descriptive statistics. Pharmacokinetic parameters for AZD0837 and its metabolites (AR-H069927 and AR-H067637) as well as for cimetidine were calculated with non-compartmental analysis using WinNonlin Professional version 4.1 (Pharsight Corporation, Mountain View, USA), and included the maximum plasma concentration $\left(C_{\max }\right)$ and area under the plasma concentration versus time curve during the dosing interval $\left(A \cup C_{\mathrm{T}}\right)$. Ratios of the true geometric means for the pharmacokinetic parameters were estimated to evaluate changes for the combination of AZD0837 and cimetidine versus when given alone. For AZD0837 and its metabolites, a mixed effect analysis of variance model (ANOVA) was used with the logarithm of $C_{\max }$ or $A \cup C_{T}$ as the response variable, period and day as fixed factors and subject as a random factor. For cimetidine pharmacokinetics, descriptive statistics were used. 


\section{RESULTS \\ Demographics}

Thirty subjects ( 21 men and 9 women) with a mean age of $64.1 \pm 3.2$ years and a mean body mass index of $26.6 \pm 2.2 \mathrm{~kg} / \mathrm{m}^{2}$ were randomised. All subjects had a creatinine clearance $>70 \mathrm{ml} / \mathrm{min}$ and only one subject was on chronic medication. In this subject, treatment with an angiotensin-converting enzyme inhibitor (enalapril) was recorded at study start and was continued during the study. All subjects completed the study within a 3-month period (first subject in 14 August and last subject out 14 November 2006).

\section{Assessments of renal function}

\section{Serum creatinine}

S-creatinine levels over time in the two treatment periods are shown in Figure 2. A 6\% increase in mean s-creatinine $(5 \mu \mathrm{mol} / \mathrm{l})$ compared with baseline was observed already during Day 1 of AZD0837 treatment, then reached a plateau and was stable during the subsequent days of administration of AZD0837. After co-administration of cimetidine with AZD0837, a 21\% increase $(17 \mu \mathrm{mol} / \mathrm{l})$ compared with baseline was observed. During placebo treatment s-creatinine remained stable until the start of cimetidine treatment (Day 6 ) when a rapid $17 \%$ increase (14 $\mu \mathrm{mol} / \mathrm{l})$ was observed, reaching a plateau 2 days later. At follow up, s-creatinine returned to baseline and all subjects had values within the normal range.

\section{Serum cystatin $C$}

No increase in s-cystatin C during the treatment period with AZD0837 was observed (Figure 3).

\section{Glomerular filtration rate}

Individual GFR values on Day 5 of the AZD0837/placebo treatment period are shown in Figure 4. The diagonal reference lines indicate a change from placebo by $\pm 10 \%$. Descriptive statistics for GFR on Day 5 by treatment period and differences between treatments are displayed in Table 1. A mean difference in GFR of $-1.6 \mathrm{ml} / \mathrm{min} / 1.73 \mathrm{~m}^{2}(90 \% \mathrm{Cl}$ : -3.7 to 0.5$)$ was estimated at Day 5 of the AZD0837 treatment period compared with the placebo period. One subject had an unreliable GFR measurement when on AZD0837; upon excluding this subject the mean difference in GFR between treatments was $-0.7 \mathrm{ml} / \mathrm{min} / 1.73 \mathrm{~m}^{2}(90 \% \mathrm{Cl}:-2.3$ to 0.9 ). Since the lower bound of the $\mathrm{Cl}$ was no less than $-5 \mathrm{ml} / \mathrm{min}$ it could be concluded that AZD0837 had no clinically relevant effect on GFR.

\section{Endogenous creatinine clearance}

Endogenous $\mathrm{CrCl}$ was measured on Day 5 (without cimetidine) and Day 8 (with cimetidine) in the placebo and AZD0837 treatment periods, respectively. Treatment with AZD0837 resulted in 
a significant decrease in $\mathrm{CrCl}$ of $-5.7 \mathrm{ml} / \mathrm{min} / 1.73 \mathrm{~m}^{2}(95 \% \mathrm{Cl}$ : -11.3 to -0.12$)$ compared with placebo treatment. Three days of cimetidine treatment resulted in a significant decrease in $\mathrm{CrCl}$ of $-15.1 \mathrm{ml} / \mathrm{min} / 1.73 \mathrm{~m}^{2}$ (95\% Cl: -20.9 to -9.2$)$ during the placebo treatment period and $-13.5 \mathrm{ml} / \mathrm{min} / 1.73 \mathrm{~m}^{2}(95 \% \mathrm{Cl}:-19.2$ to -7.7$)$ during treatment with AZD0837. The numerically lowest $\mathrm{CrCl}$ was seen after co-administration of cimetidine and AZD0837, the estimated mean difference between placebo plus cimetidine and AZD0837 plus cimetidine being $-4.2 \mathrm{ml} / \mathrm{min} / 1.73 \mathrm{~m}^{2}$ (95\% Cl: -10.1 to 1.8$)$.

\section{Urinary markers of renal damage}

None of the urinary markers of renal damage (albumin, immunoglobulin $G$, $\alpha_{1}$-microglobulin, $\beta_{2}$-microglobulin and ACR) showed any treatment-related changes and no abnormal values were observed during the treatment periods (data not shown).

\section{Pharmacokinetics}

Co-administration of AZD0837 with cimetidine did not alter the exposure $\left(A \cup C_{\text {T }}\right.$ and $\left.C_{\max }\right)$ of AZD0837, AR-H069927 and AR-H067637. With respect to AR-H067637, the estimated ratios (with vs. without cimetidine) of the geometric means for $\mathrm{AUC}_{(0-24)}$ and $\mathrm{C}_{\max }$ were 0.971 (95\% Cl: 0.846 to 1.114 ) and 0.911 (95\% Cl: 0.781 to 1.062$)$, respectively. Furthermore, there was no relevant difference in the mean \pm standard deviation of $A U C_{T}$ and $C_{\max }$ of cimetidine when coadministered with AZD0837 (11.5 $\pm 2.84 \mu \mathrm{g} . \mathrm{h} / \mathrm{ml}$ and $2.98 \pm 0.750 \mu \mathrm{g} / \mathrm{ml})$ versus placebo (12.0 $\pm 2.84 \mu \mathrm{g} . \mathrm{h} / \mathrm{ml}$ and $3.11 \pm 0.819 \mu \mathrm{g} / \mathrm{ml})$.

\section{Safety evaluation}

Overall, there were few adverse events reported in this study, indicating that the study treatments were well tolerated (data not shown). Most adverse events had single occurrences and there was no apparent difference in the adverse event profile between the treatments. Diarrhoea was reported by one subject during the treatment period with AZD0837 alone, and this has previously been identified as a possible side effect of AZD0837 [8;9]. Due to the pharmacodynamic effect, it cannot be ruled out if AZD0837 contributed to one event of haematochezia; however, one bleeding event was also noted with placebo. One event of a thrombophlebitis can reasonably be attributed to the indwelling cannula and the repeated puncture of the vessels of the forearm.

\section{DISCUSSION}

In this study an overall mean increase of approximately $6 \%$ in s-creatinine but no change in scystatin $\mathrm{C}$ was found in elderly healthy subjects treated with AZD0837. The increase in screatinine was not accompanied by a decrease in GFR, and, since a simultaneous reduction in 


\section{1}

$\mathrm{CrCl}$ was found, this suggests that inhibition of renal tubular secretion of creatinine by AZD0837 is the likely mechanism to explain the observed increase in s-creatinine during treatment with AZD0837.

The increase in s-creatinine seen during AZD0837 treatment had a relatively rapid onset, similar to that found during cimetidine treatment, and s-creatinine concentrations reached a steady state within 24 hours. The decline in s-creatinine after withdrawal of AZD0837 and/or cimetidine also occurred rapidly and s-creatinine concentrations were close to pre-treatment values at 24 hours after stopping treatment. Accounting for the time for wash-out of AZD0837 and cimetidine, the rates of onset and offset appeared similar. The observed time pattern is consistent with an inhibition of tubular secretion of creatinine since s-creatinine has a half-life of 6 hours and a new steady-state thus should be reached by 24 hours. Similar time patterns for s-creatinine have also been found in previous studies with AZD0837 [8;9].

Cystatin $C$ is produced steadily by all types of nucleated cells in the body and is freely filtered in the glomeruli and then absorbed and degraded in the proximal tubuli. Cystatin $\mathrm{C}$ is therefore used as a marker of glomerular filtration [16]. In addition, it has been suggested that s-cystatin $C$ might be an earlier and more rapid indicator of change in GFR than s-creatinine [17]. In the present study no change in s-cystatin $\mathrm{C}$ over time was found in any of the treatment groups. An increase in s-creatinine but not in s-cystatin $C$ has also been shown in a Phase II study with AZD0837 [8]. These findings taken together indicate that the increase in s-creatinine is the result of an effect on tubular handling of creatinine instead of a direct effect on GFR.

To evaluate a potential effect of AZD0837 on renal function in this study the GFR was measured by plasma iCl (four-sample method). A clinically relevant effect of GFR was set to $10 \%$ taking into account the previously described within-individual coefficient of variation for $\mathrm{iCl}$ measurements [18]. No significant change in GFR was found during treatment with AZD0837 as compared with treatment with placebo.

Since an effect on tubular handling of creatinine had been suggested in previous studies with AZD0837 we tried to further evaluate this by co-administrating cimetidine. Cimetidine is a wellknown competitive inhibitor of the tubular secretion of creatinine via effects on the human organic cation transporter-2 (OCT2) and does not have any direct effect on GFR [5;7]. Maximum inhibition of tubular secretion of creatinine has been reported within 24 hours after start of three-times-daily dosing with $800 \mathrm{mg}$ cimetidine in young healthy subjects [19]. A slightly lower dose $(400+400+800 \mathrm{mg})$ was chosen in the present study and was given for 3 days to ensure inhibition of renal tubular secretion of creatinine. An expected reduction in endogenous 
$\mathrm{CrCl}$ by cimetidine was found both during treatment with placebo and AZD0837. The additive effect on tubular creatinine secretion by cimetidine on top of AZD0837 suggests that secretion was only partially blocked by $450 \mathrm{mg}$ of AZD0837 and that AZD0837 is a weaker inhibitor of tubular creatinine secretion than cimetidine. The numerically lowest $\mathrm{CrCl}$ was seen after coadministration of cimetidine and AZD0837, thus indicating that the cimetidine dose used in this study by itself did not completely block tubular creatinine secretion. A pharmacokinetic drugdrug interaction between AZD0837 and cimetidine is unlikely since no effect on the AUC and Cmax of AZD0837 or its metabolites was found in this study.

An effect of AZD0837 on inhibition of tubular secretion of creatinine is further supported by in vitro data from wild-type and OCT2-transfected HEK293 cells showing that AZD0837 is an inhibitor of basolateral OCT2-mediated transport of creatinine. AZD0837, AR-H069927 and ARH067637 inhibited OCT2-mediated transport of creatinine $(10 \mu \mathrm{M})$ with $\mathrm{IC}_{50}$ values of 37,27 and $0.7 \mu \mathrm{M}$, respectively. Cimetidine, used as a positive OCT2 inhibitor, inhibited the OCT2 transport of creatinine with an $\mathrm{IC}_{50}$ value of $21 \mu \mathrm{M}$ (unpublished data). A benign effect on renal handling of creatinine was further supported in the present study by the fact that no treatmentrelated changes in renal damage markers were found during the treatment periods.

Recently, the apical transporter system multidrug and toxin extrusion-1 (MATE1) protein has been reported to potentially be involved in the tubular secretion of creatinine [20]. AZD0837 and its metabolites were identified as MATE1 inhibitors of varying strength (with $\mathrm{IC}_{50}$ values of 70.6 , 29.0 and $0.28 \mu \mathrm{M}$ for AZD0837, AR-H069927 and AR-H067637, respectively [unpublished data]). Inhibition of MATE1 could thus be an additional benign mechanism for inhibition of creatinine secretion in the kidney.

Another potential explanation to elevations in s-creatinine is an increased production of creatinine. Unfortunately, no markers of muscle metabolism were measured in this study; however, none of the participating patients reported any muscular symptoms. In addition, no significant mean difference in total excreted amount of creatinine was found at Day 5 between AZD0837 and placebo $(-0.13 \mathrm{mmol}$ [95\% $\mathrm{Cl}$ : -0.90 to -0.63$])$, arguing against a change in creatinine production.

This study was conducted in healthy elderly subjects in order to assess markers of renal function in a population similar to the population that potentially will be treated with AZD0837 in the future. To minimise the influence of other medications the use of concomitant medications in the study was restricted. A placebo-controlled cross-over design was chosen to enable intraindividual subject evaluation and to minimise the time effects and increase the power to detect 
potential changes in glomerular filtration. The length of the washout period was chosen to minimise the potential carry-over effect between the treatment periods. The lengths of the treatment periods were selected to ensure that steady-state conditions were achieved with regard to the plasma levels of AZD0837 and its metabolites on Day 5, the first day of renal assessments.

In conclusion, an overall increase of approximately $6 \%$ in s-creatinine but no change in scystatin $\mathrm{C}$ was found in elderly healthy subjects treated with AZD0837. The increase in screatinine was not accompanied by a decrease in GFR, as measured by plasma clearance of iohexol. These findings, together with unpublished in vitro data, suggest that inhibition of renal tubular secretion of creatinine is a likely mechanism resulting in the observed increase in screatinine during treatment with AZD0837.

\section{ACKNOWLEDGEMENTS}

We would like to thank Bengt Hamrén and Johan E Karlsson at AstraZeneca R\&D Mölndal, Sweden, for their scientific advice in the planning of this study. The study was funded by AstraZeneca. Editorial assistance for the compilation of this manuscript was provided by Lars Elvelin, AstraZeneca R\&D Mölndal, Sweden, and by Lee Kempster, MediTech Media (UK), and was funded by AstraZeneca.

\section{CONFLICTS OF INTEREST}

K-M Schützer, S Zetterstrand, UG Eriksson, and K Wåhlander are employees of AstraZeneca, Sweden, with stock ownership. M Svensson has received funding for consultancy from AstraZeneca. 


\section{Reference list}

1. Tett SE, Kirkpatrick CM, Gross AS, McLachlan AJ (2003) Principles and clinical application of assessing alterations in renal elimination pathways. Clin Pharmacokinet 42: 1193-1211

2. Burkhardt H, Bojarsky G, Gretz N, Gladisch R (2002) Creatinine clearance, CockcroftGault formula and cystatin $C$ : estimators of true glomerular filtration rate in the elderly? Gerontology 48: 140-146

3. Herget-Rosenthal S, Bokenkamp A, Hofmann W (2007) How to estimate GFR-serum creatinine, serum cystatin $C$ or equations? Clin Biochem 40: 153-161

4. Epstein BJ (2004) Elevations in serum creatinine concentration: concerning or reassuring? Pharmacotherapy 24: 697-702

5. Andreev E, Koopman M, Arisz L (1999) A rise in plasma creatinine that is not a sign of renal failure: which drugs can be responsible? J Intern Med 246: 247-252

6. Brater DC (2002) Measurement of renal function during drug development. Br J Clin Pharmacol 54: 87-95

7. Urakami Y, Kimura N, Okuda M, Inui K (2004) Creatinine transport by basolateral organic cation transporter hOCT2 in the human kidney. Pharm Res 21: 976-981

8. Lip GYH, Rasmussen LH, Olsson SB, Jensen EC, Persson AL, Eriksson U, Wåhlander $K F C$, on behalf of the Steering Committee (2009) Oral direct thrombin inhibitor AZD0837 for the prevention of stroke and systemic embolism in patients with non-valvular atrial fibrillation: a randomised dose-guiding, safety and tolerability study of four doses of AZD0837 versus vitamin K antagonists. Eur Heart J 30: 2897-2907

9. Olsson SB, Rasmussen LH, Tveit A, Jensen P, Wessman P, Paniflov S, Wåhlander $K$ (2010) Safety and tolerability of an immediate-release formulation of the oral direct thrombin inhibitor AZD0837 in the prevention of stroke and systemic embolism in patients with atrial fibrillation. Thromb Haemost 103: doi: 10.1160/TH09-07-0509

10. Deinum J, Mattsson C, Inghardt T, Elg M (2009) Biochemical and pharmacological effects of the direct thrombin inhibitor AR-H067637. Thromb Haemost 101: 1051-1059

11. Cullberg M, Schutzer K-M, Eriksson U, Alenhag E-L, Malm A, Johansson S, Wåhlander K (2007) Safety, pharmacokinetics and pharmacodynamics of the oral direct thrombin inhibitor AZD0837 in young healthy volunteers. Basic Clin Pharmacol Toxicol 101: abstr 206

12. Johansson S, Cullberg M, Eriksson UG, Schützer K-M, Wessman $P$, Holmberg $M$, Cullbrand E, Wåhlander K (2009) Pharmacokinetics and pharmacodynamics of the oral direct thrombin inhibitor AZD0837 after repeated administration of ascending doseregimens to healthy subjects. Basic Clin Pharmacol Toxicol 105: abstr TP78

13. Johansson S, Cullberg M, Ekdahl E, Wåhlander K, Dunér K, Eriksson UG (2009) Pharmacokinetics of AZD0837, a novel direct thrombin inhibitor, after oral and intravenous administration to healthy male volunteers. Basic \& Clinical Pharmacology and Toxicology 105: abstr TP79 
1

2

3

14. Cockcroft DW, Gault MH (1976) Prediction of creatinine clearance from serum creatinine. Nephron 16: 31-41

15. Hojs R, Bevc S, Ekart R, Gorenjak M, Puklavec L (2006) Serum cystatin $C$ as an endogenous marker of renal function in patients with mild to moderate impairment of kidney function. Nephrol Dial Transplant 21: 1855-1862

16. Dharnidharka VR, Kwon C, Stevens $G$ (2002) Serum cystatin $C$ is superior to serum creatinine as a marker of kidney function: a meta-analysis. Am J Kidney Dis 40: 221-226

17. Herget-Rosenthal S, Pietruck F, Volbracht L, Philipp T, Kribben A (2005) Serum cystatin $C$--a superior marker of rapidly reduced glomerular filtration after uninephrectomy in kidney donors compared to creatinine. Clin Nephrol 64: 41-46

18. Sterner G, Frennby B, Hultberg B, Almen T (1996) lohexol clearance for GFRdetermination in renal failure--single or multiple plasma sampling? Nephrol Dial Transplant 11: $521-525$

19. van Acker BA, Koomen GC, Koopman MG, de Waart DR, Arisz L (1992) Creatinine clearance during cimetidine administration for measurement of glomerular filtration rate. Lancet 340: 1326-1329

20. Sato T, Masuda S, Yonezaw A, Tanihara Y, Katsura T, Inui K (2008). Transcellular transport of organic cations in double-transfected MDCK cells expressing human organic cation transporters hOCT1/hMATE1 and hOCT2/hMATE1. Biochem Pharmacol 76: 894903 
Table 1. Descriptive statistics for glomerular filtration rate (GFR) $\left(\mathrm{ml} / \mathrm{min} / 1.73 \mathrm{~m}^{2}\right)$ on Day 5, and absolute and relative differences between treatments

\begin{tabular}{lll}
\hline & Means \pm SD & Range \\
\hline AZD0837 & $87.6 \pm 10.9$ & $59^{\mathrm{a}}-108$ \\
Placebo & $88.8 \pm 9.3$ & $73-108$ \\
Difference, & $-1.5 \pm 7.2$ & $-27-14$ \\
$\mathrm{ml} / \mathrm{min} / 1.73 \mathrm{~m}^{2}$ & & \\
Difference, $\%$ & $-1.5 \pm 8.3$ & $-31-17$
\end{tabular}

${ }^{\mathrm{a}}$ This subject most likely had an erroneous analysis result during AZD0837 administration, according to the laboratory; the next higher GFR value in a subject was 74 . 


\title{
Reversible elevations of serum creatinine but no effect on glomerular filtration during treatment with the direct thrombin inhibitor AZD0837
}

\author{
K-M Schützer ${ }^{1}$, MK Svensson ${ }^{2}$, S Zetterstrand ${ }^{1}$, UG Eriksson ${ }^{1}$, K Wåhlander $^{1}$ \\ ${ }^{1}$ AstraZeneca R\&D, Mölndal, Sweden \\ ${ }^{2}$ Department of Molecular and Clinical Medicine, Sahlgrenska University Hospital, Gothenburg, \\ Sweden
}

Correspondence: Kajs-Marie Schützer, CVGI Clinical TA, AstraZeneca R\&D MöIndal, S-431 83 Mölndal, Sweden.

E-mail: kajs-marie.schutzer@astrazeneca.com

Tel: +46317762767

Mobile: +46 705656576

Fax: +4631776 3759

AstraZeneca study code: D1250C00033

Keywords: thrombin inhibitor, renal function, glomerular filtration rate, creatinine, tubular secretion, tubular transporter proteins 


\begin{abstract}
Purpose: Reversible mean increases in serum creatinine ( 10\%) have been observed during the clinical investigations of the oral direct thrombin inhibitor AZD0837. The aim of this study was to evaluate whether the increase in s-creatinine is due to a decrease in renal glomerular filtration rate (GFR) or inhibition of tubular secretion of creatinine.
\end{abstract}

Methods: Thirty healthy subjects aged 60-71 years were included in an open-label, randomised, placebo-controlled, two-way crossover study (D1250C00033) with AZD0837 450 mg extended-release formulation once daily for 8 days. Cimetidine was co-administered on Days 6-8 during both treatment periods. Blood and urine samples were collected for assessment of s-creatinine, s-cystatin $\mathrm{C}$, endogenous creatinine clearance $(\mathrm{CrCl})$ and urinary markers of renal damage. GFR was measured by the plasma clearance of iohexol.

Results: A 6\% increase in mean s-creatinine, but no increase in s-cystatin C, was observed during treatment with AZD0837. Co-administration of cimetidine resulted in a $21 \%$ increase in screatinine. A significant decrease in $\mathrm{CrCl}$ was found during AZD0837 treatment compared with placebo $(-5.73 \mathrm{ml} / \mathrm{min}$; $95 \% \mathrm{Cl}-11.3$ to -0.12$)$. No significant difference in GFR $(-1.6$ $\mathrm{ml} / \mathrm{min} / 1.73 \mathrm{~m}^{2} ; 90 \% \mathrm{Cl}-3.7$ to 0.5$)$ was seen during treatment with AZD0837 versus placebo. No changes in renal damage markers were found during the treatment periods.

Conclusions: An increase in s-creatinine, a decrease in $\mathrm{CrCl}$, but no decrease in GFR, were found during treatment with AZD0837. Findings suggest that inhibition of renal tubular secretion of creatinine is the likely cause of the observed increase in s-creatinine.

Word count $=249$ words 


\section{INTRODUCTION}

Creatinine is a non-protein waste product of creatine phosphate metabolism by skeletal muscle tissue. Creatinine production is continuous and is proportional to muscle mass. Creatinine is freely filtered in the kidney and therefore the serum creatinine (s-creatinine) level is dependent on glomerular filtration rate (GFR), but is also influenced by active renal tubular excretion of creatinine, diet and muscular mass [1;2]. S-creatinine is often used as an indicator of renal function both in clinical practice and during drug development [3].

During drug development, elevations in s-creatinine, raising the question of nephrotoxicity have occasionally been found. Sometimes this may indeed be a reflection of adverse renal effects and in other cases due to a beneficial renal functional effect, such as the renal haemodynamic alterations of angiotensin-converting enzyme inhibitors and angiotensin receptor blockers [4], or due to reversible benign inhibition of the renal tubular secretion of creatinine as seen with cimetidine [5-7].

AZD0837 is an oral direct thrombin inhibitor currently under clinical development for stroke prevention in atrial fibrillation [8;9]. AZD0837 is rapidly absorbed and bioconverted into its active form, AR-H067637, via an intermediate metabolite, AR-H069927 [10-12]. AZD0837 is only to a minor degree excreted into the urine [13]. During clinical development of AZD0837 a reversible increase in mean s-creatinine of approximately $10 \%$ has been found. The objective of the present study was to investigate potential mechanisms for this increase in s-creatinine and to evaluate whether it may be due to a decrease in renal GFR or inhibition of tubular secretion of creatinine.

\section{METHODS}

\section{Subjects}

Healthy men and women, aged 60-75 years, with normal clinical and laboratory findings including a normal renal function (> $70 \mathrm{ml} / \mathrm{min}$ ), as estimated by creatinine clearance $(\mathrm{CrCl})$ according to the Cockcroft-Gault formula [14], a body mass index of $18-30 \mathrm{~kg} / \mathrm{m}^{2}$ and who gave written, informed consent prior to enrolment were eligible to participate in the study. Exclusion criteria included significant recurrent illness, a history of bleeding or thrombotic disorder, a history of, or ongoing, severe allergy or hypersensitivity, hypersensitivity to X-ray contrast medium, cardiovascular, hepatic or significant gastrointestinal disease, or a positive HIV or hepatitis B or $\mathrm{C}$ test. The use of anticoagulant, antiplatelet (including aspirin), fibrinolytic or nonsteroidal anti-inflammatory drugs was not permitted from 2 weeks prior to the study until completion. 
The study was approved by the independent Institutional Review Board/Research Ethics Committee Berlin, Germany and the national medical agency BfArm, Germany. The study was performed in compliance with the Declaration of Helsinki.

\section{Study design}

This was an open-label, randomised, placebo-controlled, two-way crossover Phase I study (D1250C00033) with two treatment periods of 8 days each, separated by a washout period of 10-21 days as shown in Figure 1. Repeated doses of AZD0837 450 mg extended-release formulation (three $150 \mathrm{mg}$ tablets) were given as a once-daily administration in the morning for 8 days in one period and corresponding placebo tablets were given during the other period. Cimetidine $\left(\right.$ Tagamet $^{\circledR}$, GlaxoSmithKline) was co-administered on Days 6-8 in both periods in a three-times-daily regimen of $400+400+800 \mathrm{mg}$ as a positive control for inhibition of tubular secretion of creatinine. A pre-entry screening visit, including an overall health examination, was conducted within 14 days prior to the first study day. This comprised a medical history, history of bleeding and thrombotic occurrences, physical examination, 12-lead electrocardiogram and measurement of blood pressure, heart rate and laboratory status (haematology, clinical chemistry, urinalysis and coagulation analysis [activated partial thromboplastin time (APTT)]). Laboratory measurements were repeated during both treatment periods: before administration of study drug on Day 1, on Day 5 and Day 8 before administration, and 7-10 days after completion of last treatment period. Subjects whose 24-hour APTT values after last dose were more than 10 seconds greater than their pre-dose values were required to remain at the study site until the values had normalised.

\section{Assessments of renal function}

\section{Serum creatinine}

S-creatinine was measured before every AZD0837/placebo dose on Days 1-8 and in the mornings of Days 9 and 10. In addition, s-creatinine was measured 12 hours after AZD0837/placebo dose on Days 5 and 8. S-creatinine was analysed by routine spectrophotometry methods (Architect c8000, Abbott GmbH \& Co. KG, Wiesbaden-Delkenheim, Germany).

\section{Serum cystatin $C$}

Serum cystatin C (s-cystatin C), an additional glomerular filtration marker, was determined before every AZD0837/placebo dose on Days 1, 5 and 8 and in the morning of Day 10 [15]. Scystatin $\mathrm{C}$ was analysed by routine methods (Image immunochemistry system, Beckman Coulter GmbH, Krefeld, Germany). 


\section{Glomerular filtration rate}

GFR was determined by plasma clearance of iohexol (iCl) (four-sample method) on Day 5 in each treatment period. lohexol $300 \mathrm{mg} / \mathrm{ml}$ was given as a $5 \mathrm{ml}$ intravenous injection 3 hours after the AZD0837/placebo dose. Blood ( $7.5 \mathrm{ml}$ in heparinised tubes) for determination of the plasma concentration of iohexol was taken at pre-dose and at 1,2 and 4 hours after the injection of iohexol. A standardised high water intake (>1000 ml) was given before injection of iohexol (Omnipaque ${ }^{\circledR}$, Nycomed Amersham Health, Cork, Ireland) to ensure an adequate urine production. The plasma samples for $\mathrm{iCl}$ were analysed using high-performance liquid chromatography (Renalyzer PRX 90, Provalid AB, Lund, Sweden) at the Department of Clinical Chemistry, Sahlgrenska University Hospital, Sweden.

\section{Endogenous creatinine clearance}

Endogenous $\mathrm{CrCl}$ was measured by analysis of 24-hour urine collections on Days 5 and 8 . The bladder was emptied before the urine collection period started. A $10 \mathrm{ml}$ sample was taken from all urine from the total collection period (0-24 hours). A blood sample for analysis of creatinine ( $2.7 \mathrm{ml}$ serum separating tube) was drawn after 12 hours (mid-period). The urine and serum analyses of creatinine were carried out using routine spectrophotometry methods (Architect c8000, Abbott GmbH \& Co. KG, Wiesbaden-Delkenheim, Germany).

\section{Urinary markers of renal damage}

Urinary albumin, immunoglobulin $G, \alpha_{1}$-microglobulin and $\beta_{2}$-microglobulin were determined in a 12-hour urine collection starting in the evening before the AZD0837/placebo dose on Days 1 and 5. Urinary albumin and creatinine (albumin/creatinine ratio; ACR) were determined in the 24-hour urine collection on Days 5 and 8. Urinary markers were analysed by standard methods at the Department of Clinical Chemistry, Sahlgrenska University Hospital, Gothenburg, Sweden.

\section{Pharmacokinetics}

Plasma samples for measurement of AZD0837, AR-H069927 (the intermediary metabolite) and AR-H067637 (the active form of AZD0837) concentrations were analysed by Analytico Medinet (AM) B.V., the Netherlands. For determination of plasma concentration, reversed-phase liquid chromatography-tandem mass spectrometry after solid-phase extraction was used. The limit of quantification (LOQ) was $10 \mathrm{nmol} / \mathrm{l}$ for all analytes. The method was developed for $250 \mu \mathrm{l}$ human citrate plasma, and plasma concentrations were adjusted for the dilution of blood with citrate buffer in the sampling tubes. AZD0837, AR-H069927 and AR-H067637 were extracted from human plasma by means of an automated solid-phase extraction (extraction columns: $1 \mathrm{ml}$ 
ISOLUTE C6-column 25 mg). Chromatography was performed on an Hypersil HyPurity C18, $5 \mu \mathrm{m}(100 \mathrm{~mm} \times 2.1 \mathrm{~mm})$ protected by a C18 pre column at a flow of $0.75 \mathrm{ml} / \mathrm{min}$. The mass spectrometer used was an Applied Biosystems/MDS Sciex API-3000 system with turbo-ion spray interface and Analyst Software. Cimetidine concentrations in plasma were determined by PRA International - Early Development Services, Bioanalytical Laboratory, the Netherlands, using liquid chromatography with ultraviolet detection after solid-phase extraction. The LOQ was $0.10 \mu \mathrm{g} / \mathrm{ml}$.

\section{Statistical analysis}

This trial set out to test whether AZD0837 would affect GFR. A clinically relevant effect on GFR was considered to be $10 \%$ (for example, a change in GFR of $7 \mathrm{ml} / \mathrm{min} / 1.73 \mathrm{~m}^{2}$ in a population with a mean GFR of $70 \mathrm{ml} / \mathrm{min} / 1.73 \mathrm{~m}^{2}$ ), and the "no effect limit" was set to a difference of -5 $\mathrm{ml} / \mathrm{min} / 1.73 \mathrm{~m}^{2}$. With 24 evaluable subjects the power to conclude "no effect" was $90 \%$, given that AZD0837 did not affect GFR, at the significance level of $5 \%$, and assuming a standard deviation of $8 \mathrm{ml} / \mathrm{min}$ of the difference in GFR. Since the previously observed elevation in screatinine with AZD0837 could correspond to a potential reduction in GFR, only a reduction in GFR was considered clinically relevant, and a one-sided test of significance was therefore used. GFR was analysed in an analysis of variance (ANOVA) model with fixed factors for treatment, sequence and period, and a random factor for subject. To test for "no effect" a two-sided 90\% confidence interval $(\mathrm{Cl})$ for differences in treatment means was constructed. If the lower bound of this $\mathrm{Cl}$ (corresponding to the lower bound of the one-sided $95 \% \mathrm{Cl}$ ) was no less than -5 $\mathrm{ml} / \mathrm{min}$ it was to be concluded that there was no clinically relevant effect on GFR by AZD0837. Endogenous $\mathrm{CrCl}$, s-creatinine and s-cystatin $\mathrm{C}$ were analysed using descriptive statistics. Pharmacokinetic parameters for AZD0837 and its metabolites (AR-H069927 and AR-H067637) as well as for cimetidine were calculated with non-compartmental analysis using WinNonlin Professional version 4.1 (Pharsight Corporation, Mountain View, USA), and included the maximum plasma concentration $\left(C_{\max }\right)$ and area under the plasma concentration versus time curve during the dosing interval $\left(A \cup C_{\mathrm{T}}\right)$. Ratios of the true geometric means for the pharmacokinetic parameters were estimated to evaluate changes for the combination of AZD0837 and cimetidine versus when given alone. For AZD0837 and its metabolites, a mixed effect analysis of variance model (ANOVA) was used with the logarithm of $C_{\max }$ or $A \cup C_{T}$ as the response variable, period and day as fixed factors and subject as a random factor. For cimetidine pharmacokinetics, descriptive statistics were used. 


\section{RESULTS \\ Demographics}

Thirty subjects ( 21 men and 9 women) with a mean age of $64.1 \pm 3.2$ years and a mean body mass index of $26.6 \pm 2.2 \mathrm{~kg} / \mathrm{m}^{2}$ were randomised. All subjects had a creatinine clearance $>70 \mathrm{ml} / \mathrm{min}$ and only one subject was on chronic medication. In this subject, treatment with an angiotensin-converting enzyme inhibitor (enalapril) was recorded at study start and was continued during the study. All subjects completed the study within a 3-month period (first subject in 14 August and last subject out 14 November 2006).

\section{Assessments of renal function}

\section{Serum creatinine}

S-creatinine levels over time in the two treatment periods are shown in Figure 2. A 6\% increase in mean s-creatinine ( $5 \mu \mathrm{mol} / \mathrm{l})$ compared with baseline was observed already during Day 1 of AZD0837 treatment, then reached a plateau and was stable during the subsequent days of administration of AZD0837. After co-administration of cimetidine with AZD0837, a 21\% increase (17 $\mu \mathrm{mol} / \mathrm{l})$ compared with baseline was observed. During placebo treatment s-creatinine remained stable until the start of cimetidine treatment (Day 6) when a rapid 17\% increase (14 $\mu \mathrm{mol} / \mathrm{l})$ was observed, reaching a plateau 2 days later. At follow up, s-creatinine returned to baseline and all subjects had values within the normal range.

\section{Serum cystatin $C$}

No increase in s-cystatin $C$ during the treatment period with AZD0837 was observed (Figure 3).

\section{Glomerular filtration rate}

Individual GFR values on Day 5 of the AZD0837/placebo treatment period are shown in Figure 4. The diagonal reference lines indicate a change from placebo by $\pm 10 \%$. Descriptive statistics for GFR on Day 5 by treatment period and differences between treatments are displayed in Table 1. A mean difference in GFR of $-1.6 \mathrm{ml} / \mathrm{min} / 1.73 \mathrm{~m}^{2}(90 \% \mathrm{Cl}:-3.7$ to 0.5$)$ was estimated at Day 5 of the AZD0837 treatment period compared with the placebo period. One subject had an unreliable GFR measurement when on AZD0837; upon excluding this subject the mean difference in GFR between treatments was $-0.7 \mathrm{ml} / \mathrm{min} / 1.73 \mathrm{~m}^{2}(90 \% \mathrm{Cl}:-2.3$ to 0.9 ). Since the lower bound of the $\mathrm{Cl}$ was no less than $-5 \mathrm{ml} / \mathrm{min}$ it could be concluded that AZD0837 had no clinically relevant effect on GFR.

\section{Endogenous creatinine clearance}

Endogenous $\mathrm{CrCl}$ was measured on Day 5 (without cimetidine) and Day 8 (with cimetidine) in the placebo and AZD0837 treatment periods, respectively. Treatment with AZD0837 resulted in 
a significant decrease in $\mathrm{CrCl}$ of $-5.7 \mathrm{ml} / \mathrm{min} / 1.73 \mathrm{~m}^{2}(95 \% \mathrm{Cl}$ : -11.3 to -0.12$)$ compared with placebo treatment. Three days of cimetidine treatment resulted in a significant decrease in $\mathrm{CrCl}$ of $-15.1 \mathrm{ml} / \mathrm{min} / 1.73 \mathrm{~m}^{2}$ (95\% Cl: -20.9 to -9.2$)$ during the placebo treatment period and $-13.5 \mathrm{ml} / \mathrm{min} / 1.73 \mathrm{~m}^{2}(95 \% \mathrm{Cl}:-19.2$ to -7.7$)$ during treatment with AZD0837. The numerically lowest $\mathrm{CrCl}$ was seen after co-administration of cimetidine and AZD0837, the estimated mean difference between placebo plus cimetidine and AZD0837 plus cimetidine being $-4.2 \mathrm{ml} / \mathrm{min} / 1.73 \mathrm{~m}^{2}$ (95\% Cl: -10.1 to 1.8$)$.

\section{Urinary markers of renal damage}

None of the urinary markers of renal damage (albumin, immunoglobulin $G$, $\alpha_{1}$-microglobulin, $\beta_{2}$-microglobulin and ACR) showed any treatment-related changes and no abnormal values were observed during the treatment periods (data not shown).

\section{Pharmacokinetics}

Co-administration of AZD0837 with cimetidine did not alter the exposure $\left(A \cup C_{\text {T }}\right.$ and $\left.C_{\max }\right)$ of AZD0837, AR-H069927 and AR-H067637. With respect to AR-H067637, the estimated ratios (with vs. without cimetidine) of the geometric means for $\mathrm{AUC}_{(0-24)}$ and $\mathrm{C}_{\max }$ were $0.971(95 \% \mathrm{Cl}$ : 0.846 to 1.114 ) and 0.911 (95\% Cl: 0.781 to 1.062$)$, respectively. Furthermore, there was no relevant difference in the mean \pm standard deviation of $A U C_{T}$ and $C_{\max }$ of cimetidine when coadministered with AZD0837 (11.5 $\pm 2.84 \mu \mathrm{g} . \mathrm{h} / \mathrm{ml}$ and $2.98 \pm 0.750 \mu \mathrm{g} / \mathrm{ml})$ versus placebo (12.0 $\pm 2.84 \mu \mathrm{g} . \mathrm{h} / \mathrm{ml}$ and $3.11 \pm 0.819 \mu \mathrm{g} / \mathrm{ml})$.

\section{Safety evaluation}

Overall, there were few adverse events reported in this study, indicating that the study treatments were well tolerated (data not shown). Most adverse events had single occurrences and there was no apparent difference in the adverse event profile between the treatments. Diarrhoea was reported by one subject during the treatment period with AZD0837 alone, and this has previously been identified as a possible side effect of AZD0837 [8;9]. Due to the pharmacodynamic effect, it cannot be ruled out if AZD0837 contributed to one event of haematochezia; however, one bleeding event was also noted with placebo. One event of a thrombophlebitis can reasonably be attributed to the indwelling cannula and the repeated puncture of the vessels of the forearm.

\section{DISCUSSION}

In this study an overall mean increase of approximately $6 \%$ in s-creatinine but no change in scystatin $\mathrm{C}$ was found in elderly healthy subjects treated with AZD0837. The increase in screatinine was not accompanied by a decrease in GFR, and, since a simultaneous reduction in 


\section{1}

$\mathrm{CrCl}$ was found, this suggests that inhibition of renal tubular secretion of creatinine by AZD0837 is the likely mechanism to explain the observed increase in s-creatinine during treatment with AZD0837.

The increase in s-creatinine seen during AZD0837 treatment had a relatively rapid onset, similar to that found during cimetidine treatment, and s-creatinine concentrations reached a steady state within 24 hours. The decline in s-creatinine after withdrawal of AZD0837 and/or cimetidine also occurred rapidly and s-creatinine concentrations were close to pre-treatment values at 24 hours after stopping treatment. Accounting for the time for wash-out of AZD0837 and cimetidine, the rates of onset and offset appeared similar. The observed time pattern is consistent with an inhibition of tubular secretion of creatinine since s-creatinine has a half-life of 6 hours and a new steady-state thus should be reached by 24 hours. Similar time patterns for s-creatinine have also been found in previous studies with AZD0837 [8;9].

Cystatin $C$ is produced steadily by all types of nucleated cells in the body and is freely filtered in the glomeruli and then absorbed and degraded in the proximal tubuli. Cystatin $\mathrm{C}$ is therefore used as a marker of glomerular filtration [16]. In addition, it has been suggested that s-cystatin $C$ might be an earlier and more rapid indicator of change in GFR than s-creatinine [17]. In the present study no change in s-cystatin $\mathrm{C}$ over time was found in any of the treatment groups. An increase in s-creatinine but not in s-cystatin $C$ has also been shown in a Phase II study with AZD0837 [8]. These findings taken together indicate that the increase in s-creatinine is the result of an effect on tubular handling of creatinine instead of a direct effect on GFR.

To evaluate a potential effect of AZD0837 on renal function in this study the GFR was measured by plasma iCl (four-sample method). A clinically relevant effect of GFR was set to $10 \%$ taking into account the previously described within-individual coefficient of variation for $\mathrm{iCl}$ measurements [18]. No significant change in GFR was found during treatment with AZD0837 as compared with treatment with placebo.

Since an effect on tubular handling of creatinine had been suggested in previous studies with AZD0837 we tried to further evaluate this by co-administrating cimetidine. Cimetidine is a wellknown competitive inhibitor of the tubular secretion of creatinine via effects on the human organic cation transporter-2 (OCT2) and does not have any direct effect on GFR [5;7]. Maximum inhibition of tubular secretion of creatinine has been reported within 24 hours after start of three-times-daily dosing with $800 \mathrm{mg}$ cimetidine in young healthy subjects [19]. A slightly lower dose $(400+400+800 \mathrm{mg})$ was chosen in the present study and was given for 3 days to ensure inhibition of renal tubular secretion of creatinine. An expected reduction in endogenous 
$\mathrm{CrCl}$ by cimetidine was found both during treatment with placebo and AZD0837. The additive effect on tubular creatinine secretion by cimetidine on top of AZD0837 suggests that secretion was only partially blocked by $450 \mathrm{mg}$ of AZD0837 and that AZD0837 is a weaker inhibitor of tubular creatinine secretion than cimetidine. The numerically lowest $\mathrm{CrCl}$ was seen after coadministration of cimetidine and AZD0837, thus indicating that the cimetidine dose used in this study by itself did not completely block tubular creatinine secretion. A pharmacokinetic drugdrug interaction between AZD0837 and cimetidine is unlikely since no effect on the AUC and Cmax of AZD0837 or its metabolites was found in this study.

An effect of AZD0837 on inhibition of tubular secretion of creatinine is further supported by in vitro data from wild-type and OCT2-transfected HEK293 cells showing that AZD0837 is an inhibitor of basolateral OCT2-mediated transport of creatinine. AZD0837, AR-H069927 and ARH067637 inhibited OCT2-mediated transport of creatinine $(10 \mu \mathrm{M})$ with $\mathrm{IC}_{50}$ values of 37,27 and $0.7 \mu \mathrm{M}$, respectively. Cimetidine, used as a positive OCT2 inhibitor, inhibited the OCT2 transport of creatinine with an $\mathrm{IC}_{50}$ value of $21 \mu \mathrm{M}$ (unpublished data). A benign effect on renal handling of creatinine was further supported in the present study by the fact that no treatmentrelated changes in renal damage markers were found during the treatment periods.

Recently, the apical transporter system multidrug and toxin extrusion-1 (MATE1) protein has been reported to potentially be involved in the tubular secretion of creatinine [20]. AZD0837 and its metabolites were identified as MATE1 inhibitors of varying strength (with $\mathrm{IC}_{50}$ values of 70.6 , 29.0 and $0.28 \mu \mathrm{M}$ for AZD0837, AR-H069927 and AR-H067637, respectively [unpublished data]). Inhibition of MATE1 could thus be an additional benign mechanism for inhibition of creatinine secretion in the kidney.

Another potential explanation to elevations in s-creatinine is an increased production of creatinine. Unfortunately, no markers of muscle metabolism were measured in this study; however, none of the participating patients reported any muscular symptoms. In addition, no significant mean difference in total excreted amount of creatinine was found at Day 5 between AZD0837 and placebo $(-0.13 \mathrm{mmol}[95 \% \mathrm{Cl}:-0.90$ to -0.63$])$, arguing against a change in creatinine production.

This study was conducted in healthy elderly subjects in order to assess markers of renal function in a population similar to the population that potentially will be treated with AZD0837 in the future. To minimise the influence of other medications the use of concomitant medications in the study was restricted. A placebo-controlled cross-over design was chosen to enable intraindividual subject evaluation and to minimise the time effects and increase the power to detect 
potential changes in glomerular filtration. The length of the washout period was chosen to minimise the potential carry-over effect between the treatment periods. The lengths of the treatment periods were selected to ensure that steady-state conditions were achieved with regard to the plasma levels of AZD0837 and its metabolites on Day 5, the first day of renal assessments.

In conclusion, an overall increase of approximately $6 \%$ in s-creatinine but no change in scystatin $\mathrm{C}$ was found in elderly healthy subjects treated with AZD0837. The increase in screatinine was not accompanied by a decrease in GFR, as measured by plasma clearance of iohexol. These findings, together with unpublished in vitro data, suggest that inhibition of renal tubular secretion of creatinine is a likely mechanism resulting in the observed increase in screatinine during treatment with AZD0837.

\section{ACKNOWLEDGEMENTS}

We would like to thank Bengt Hamrén and Johan E Karlsson at AstraZeneca R\&D Mölndal, Sweden, for their scientific advice in the planning of this study. The study was funded by AstraZeneca. Editorial assistance for the compilation of this manuscript was provided by Lars Elvelin, AstraZeneca R\&D Mölndal, Sweden, and by Lee Kempster, MediTech Media (UK), and was funded by AstraZeneca.

\section{CONFLICTS OF INTEREST}

K-M Schützer, S Zetterstrand, UG Eriksson, and K Wåhlander are employees of AstraZeneca, Sweden, with stock ownership. M Svensson has received funding for consultancy from AstraZeneca. 


\section{Reference list}

1. Tett SE, Kirkpatrick CM, Gross AS, McLachlan AJ (2003) Principles and clinical application of assessing alterations in renal elimination pathways. Clin Pharmacokinet 42: 1193-1211

2. Burkhardt H, Bojarsky G, Gretz N, Gladisch R (2002) Creatinine clearance, CockcroftGault formula and cystatin $C$ : estimators of true glomerular filtration rate in the elderly? Gerontology 48: 140-146

3. Herget-Rosenthal S, Bokenkamp A, Hofmann W (2007) How to estimate GFR-serum creatinine, serum cystatin $C$ or equations? Clin Biochem 40: 153-161

4. Epstein BJ (2004) Elevations in serum creatinine concentration: concerning or reassuring? Pharmacotherapy 24: 697-702

5. Andreev E, Koopman M, Arisz L (1999) A rise in plasma creatinine that is not a sign of renal failure: which drugs can be responsible? J Intern Med 246: 247-252

6. Brater DC (2002) Measurement of renal function during drug development. Br J Clin Pharmacol 54: 87-95

7. Urakami Y, Kimura N, Okuda M, Inui K (2004) Creatinine transport by basolateral organic cation transporter hOCT2 in the human kidney. Pharm Res 21: 976-981

8. Lip GYH, Rasmussen LH, Olsson SB, Jensen EC, Persson AL, Eriksson U, Wåhlander $K F C$, on behalf of the Steering Committee (2009) Oral direct thrombin inhibitor AZD0837 for the prevention of stroke and systemic embolism in patients with non-valvular atrial fibrillation: a randomised dose-guiding, safety and tolerability study of four doses of AZD0837 versus vitamin K antagonists. Eur Heart J 30: 2897-2907

9. Olsson SB, Rasmussen LH, Tveit A, Jensen P, Wessman P, Paniflov S, Wåhlander $K$ (2010) Safety and tolerability of an immediate-release formulation of the oral direct thrombin inhibitor AZD0837 in the prevention of stroke and systemic embolism in patients with atrial fibrillation. Thromb Haemost 103: doi: 10.1160/TH09-07-0509

10. Deinum J, Mattsson C, Inghardt T, Elg M (2009) Biochemical and pharmacological effects of the direct thrombin inhibitor AR-H067637. Thromb Haemost 101: 1051-1059

11. Cullberg M, Schutzer K-M, Eriksson U, Alenhag E-L, Malm A, Johansson S, Wåhlander K (2007) Safety, pharmacokinetics and pharmacodynamics of the oral direct thrombin inhibitor AZD0837 in young healthy volunteers. Basic Clin Pharmacol Toxicol 101: abstr 206

12. Johansson S, Cullberg M, Eriksson UG, Schützer K-M, Wessman $P$, Holmberg $M$, Cullbrand E, Wåhlander K (2009) Pharmacokinetics and pharmacodynamics of the oral direct thrombin inhibitor AZD0837 after repeated administration of ascending doseregimens to healthy subjects. Basic Clin Pharmacol Toxicol 105: abstr TP78

13. Johansson S, Cullberg M, Ekdahl E, Wåhlander K, Dunér K, Eriksson UG (2009) Pharmacokinetics of AZD0837, a novel direct thrombin inhibitor, after oral and intravenous administration to healthy male volunteers. Basic \& Clinical Pharmacology and Toxicology 105: abstr TP79 
14. Cockcroft DW, Gault MH (1976) Prediction of creatinine clearance from serum creatinine. Nephron 16: 31-41

15. Hojs R, Bevc S, Ekart R, Gorenjak M, Puklavec $L$ (2006) Serum cystatin $C$ as an endogenous marker of renal function in patients with mild to moderate impairment of kidney function. Nephrol Dial Transplant 21: 1855-1862

16. Dharnidharka VR, Kwon C, Stevens $G$ (2002) Serum cystatin $C$ is superior to serum creatinine as a marker of kidney function: a meta-analysis. Am J Kidney Dis 40: 221-226

17. Herget-Rosenthal S, Pietruck F, Volbracht L, Philipp T, Kribben A (2005) Serum cystatin $C$--a superior marker of rapidly reduced glomerular filtration after uninephrectomy in kidney donors compared to creatinine. Clin Nephrol 64: 41-46

18. Sterner G, Frennby B, Hultberg B, Almen T (1996) lohexol clearance for GFRdetermination in renal failure--single or multiple plasma sampling? Nephrol Dial Transplant 11: $521-525$

19. van Acker BA, Koomen GC, Koopman MG, de Waart DR, Arisz L (1992) Creatinine clearance during cimetidine administration for measurement of glomerular filtration rate. Lancet 340: 1326-1329

20. Sato T, Masuda S, Yonezaw A, Tanihara Y, Katsura T, Inui K (2008). Transcellular transport of organic cations in double-transfected MDCK cells expressing human organic cation transporters hOCT1/hMATE1 and hOCT2/hMATE1. Biochem Pharmacol 76: 894903 
Table 1. Descriptive statistics for glomerular filtration rate (GFR) $\left(\mathrm{ml} / \mathrm{min} / 1.73 \mathrm{~m}^{2}\right)$ on Day 5, and absolute and relative differences between treatments

\begin{tabular}{lll}
\hline & Means \pm SD & Range \\
\hline AZD0837 & $87.6 \pm 10.9$ & $59^{\mathrm{a}}-108$ \\
Placebo & $88.8 \pm 9.3$ & $73-108$ \\
Difference, & $-1.5 \pm 7.2$ & $-27-14$ \\
$\mathrm{ml} / \mathrm{min} / 1.73 \mathrm{~m}^{2}$ & & \\
Difference, $\%$ & $-1.5 \pm 8.3$ & $-31-17$
\end{tabular}

${ }^{\mathrm{a}}$ This subject most likely had an erroneous analysis result during AZD0837 administration, according to the laboratory; the next higher GFR value in a subject was 74 . 
On Day 5 in each period GFR was measured by plasma iCl. Endogenous $\mathrm{CrCl}$ was measured on Days 5 and 8 . o.d. = once daily, $\mathrm{R}=$ randomised, t.i.d. = three times daily

$183 \times 87 \mathrm{~mm}(600 \times 600$ DPI $)$ 
European Journal of Clinical Pharmacology

Page 30 of 32

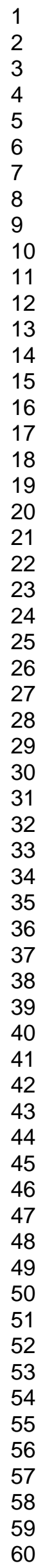

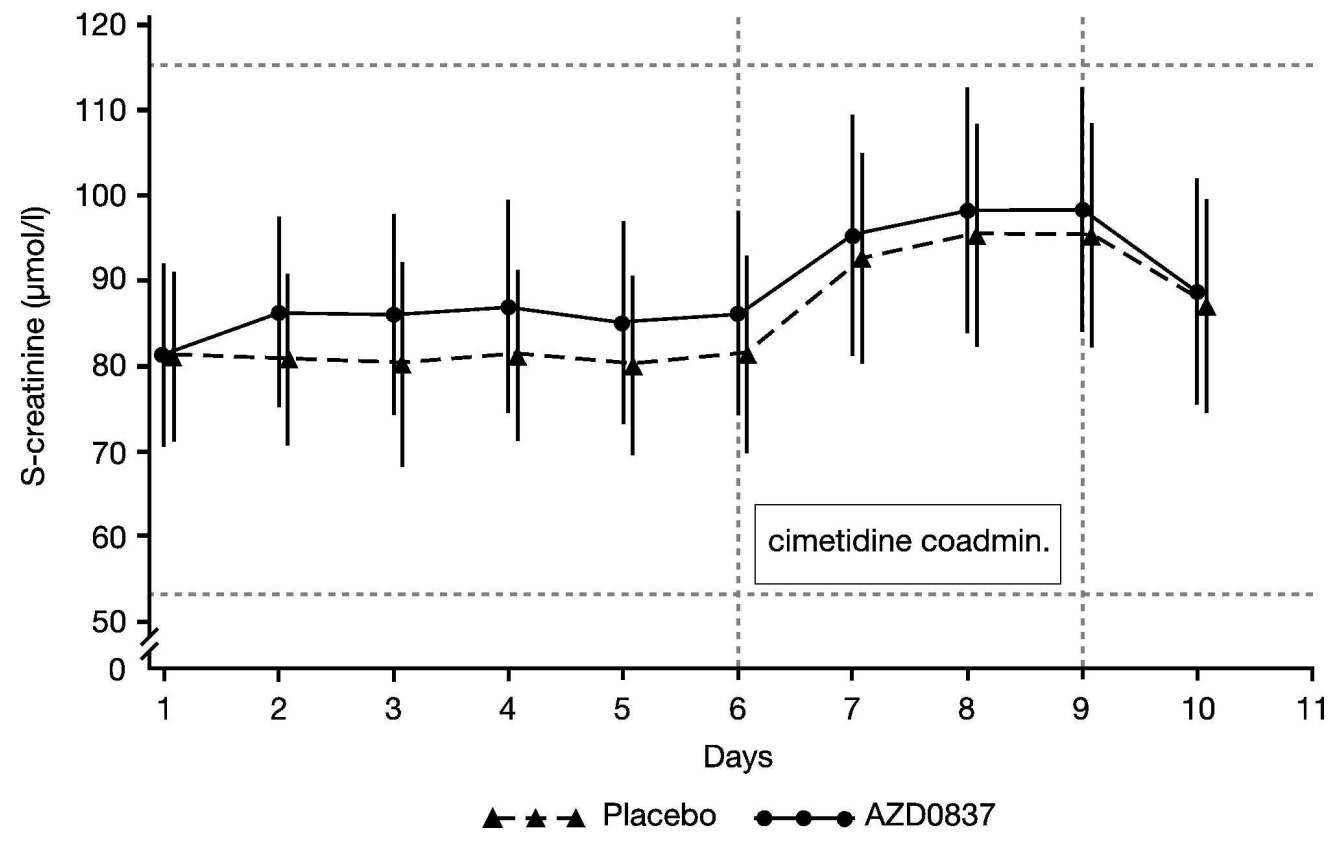

$170 \times 106 \mathrm{~mm}(600 \times 600 \mathrm{DPI})$ 
1

2

3

4

5

6

7

8

9

10

11

12

13

14

15

16

17

18

19

20

21

22

23

24

25

26

27

28

29

30

31

32

33

34

35

36

37

38

39

40

41

42

43

44

45

46

47

48

49

50

51

52

53

54

55

56

57

58

59

60

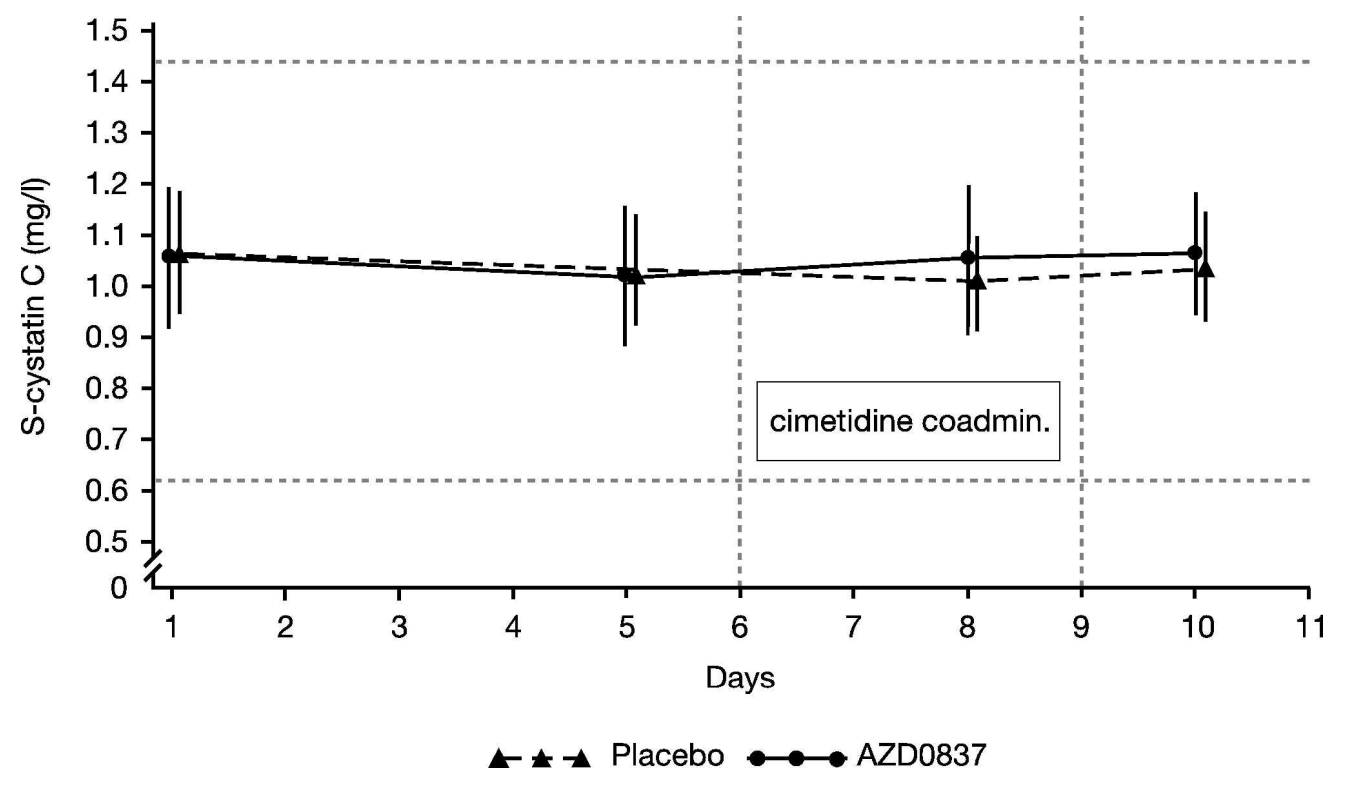

$170 \times 98 \mathrm{~mm}(600 \times 600 \mathrm{DPI})$ 


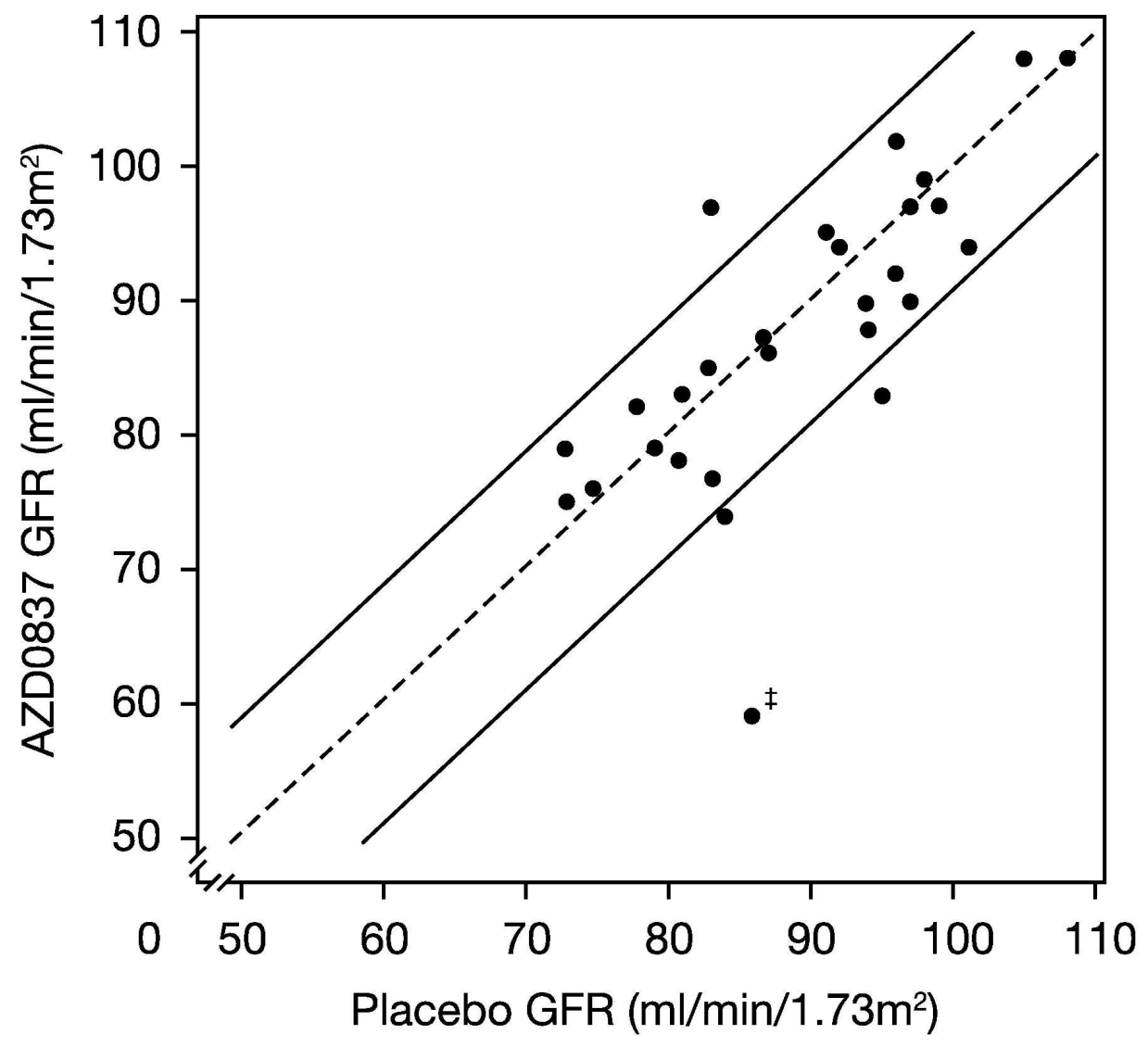

Diagonal lines indicate study population mean glomerular filtration (GFR) rate measured after treatment with placebo $\pm 10 \%$. Since the mean GFR was $89 \mathrm{ml} / \mathrm{min} / 1.73 \mathrm{~m}^{2}$, these lines correspond to a change in GFR of $8.9 \mathrm{ml} / \mathrm{min} / 1.73 \mathrm{~m}^{2}$.

¥This subject most likely had an erroneous analysis result on AZD0837 explaining the difference in calculated GFR in the two periods. 